\title{
Bullying and Aggressive Behavior among Health Care Providers: Literature Review
}

\author{
Sergey Pisklakov*, Vasanti Tilak, Anuradha Patel, Ming Xiong \\ Department of Anesthesiology and Perioperative Medicine, New Jersey Medical School, \\ University of Medicine and Dentistry of New Jersey, Newark, USA \\ Email: "pisklase@umdnj.edu
}

Received June $23^{\text {rd }}$, 2013; revised July $26^{\text {th }}$, 2013; accepted August $24^{\text {th }}, 2013$

Copyright (c) 2013 Sergey Pisklakov et al. This is an open access article distributed under the Creative Commons Attribution License, which permits unrestricted use, distribution, and reproduction in any medium, provided the original work is properly cited.

\begin{abstract}
Bullying is defined by American Psychological Association as an aggressive behavior which is intended to cause distress or harm and that involves an imbalance of power or strength between the aggressor and the victim. Bullying in the workplace is angering enough people these days to be fueling a nationwide grass-roots legislative effort to force companies to draft and enforce policies aimed at stopping it. Requiring such policies, according to those pushing the legislation, is not an attempt to spawn lawsuits, but an effort to force organizations to deal with the problem. Bullying is blamed for unnecessarily creating high costs of turnover, insurance claims and thwarted productivity. Disruptive behavior has been observed in almost all members of the healthcare team from physicians and nurses to pharmacy, radiology, and laboratory staff members. Physician behavior, however, may have the greatest impact because of the position of authority that doctors hold as members of the healthcare team. A team member may, from fear of intimidation or patronization, withhold valuable or even critical input, such as a medication error or a breakdown in adherence to safety protocols. Hospitals, departments and individual personnel need to develop a higher level of awareness of the problem both in others and in them. Anti-bullying policies should be given a higher profile.
\end{abstract}

Keywords: Aggressive Behavior; Bullying; Impact of Bullying on Healthcare Productivity and Patient Safety; Antibullying Policies

\section{Introduction}

This Bullying is defined by American Psychological Association as an aggressive behavior which is intended to cause distress or harm and that involves an imbalance of power or strength between the aggressor and the victim. A more objective-if somewhat wordy - definition used by Swedish workers is that bullying emerges when one or several persons over a period of time persistently perceive themselves to be on the receiving end of negative actions from one or several persons in a situation where the one at the receiving end has difficulty in defending him or herself against these actions. This definition incorporates the subjective feelings of the person on the receiving end, even where an individual may have behaved aggressively but with no intention to harm. It puts an onus on each individual to be mindful of the effect of their actions on others. It does not offer protection to those falsely accused of bullying. The main features of this definition are negative behaviors, persistence over time and an imbalance of power (Einharsen et al., 1994). Bullying can be physical, relational, peer sexual harassment and stereotyping. It is a way to gain power (Kozlowska et al., 1997).

Bullying in the workplace is angering people these days. It is fueling a nationwide grass-roots legislative effort to force companies to draft and enforce policies aimed at stopping it. Re-

\footnotetext{
"Corresponding author.
}

quiring such policies is not an attempt to spawn lawsuits. It is an effort to force organizations to deal with the problem. Bullying is blamed for unnecessarily creating high costs of turnover, insurance claims and thwarted productivity (Rosenstein \& O’Daniel, 2005).

\section{Necessity to Create Antibullying Policies}

In January 2009, a new standard issued by the Joint Commission [formerly JCAHO] went into effect. It requires hospitals to have "a code of conduct that defines acceptable, disruptive, and inappropriate staff behaviors" and for its "leaders [to] create and implement a process for managing disruptive and inappropriate staff behaviors.” The rationale for the standard states: "Leaders must address disruptive behavior of individuals working at all levels of the [organization], including management, clinical and administrative staff, licensed independent practitioners, and governing body members.” A Joint Commission sentinel alert includes "uncooperative attitudes" and "condescending language or voice intonation and impatience with questions" as disruptive behaviors. The Joint Commission's first-ever alert about the problem is the latest industry effort to address an issue that has challenged the medical community for years (The Joint Commission, 2009). Suggested actions include systems to detect and deter unprofessional behavior; more civil responses to patients and families who witness bad acts; and overall train- 
ing in "basic business etiquette," including phone skills and people skills for all employees (Joint Commission-Sentinel Event Alert, 2008). Administrative response to bullying has been so far ineffective. In some cases no action was taken. This lack of action could lead to serious liabilities since these incidents are not only about bullying, but also sexual harassment and discrimination.

Disruptive behavior has been observed in almost all members of the healthcare team-from physicians and nurses to pharmacy, radiology, and laboratory staff members. Physician behavior, however, may have the biggest impact because of the position of power that doctors hold as members of the healthcare team (Quine, 2002). A team member may, from fear of intimidation or patronization, withhold valuable or even critical input, such as a medication error or a breakdown in adherence to safety protocols (Rosenstein, 2005).

To ensure good patient care and respect among all healthcare professionals is at the very foundation of the ethics advocated by the American Medical Association. Intimidating, condescending, off-putting, or discouraging behavior by the physician inhibits positive team work. If OR staff works sub optimally because of disruptive behavior by the physician or another team member, overall care quality is compromised and patient safety is threatened. To mitigate these risks, healthcare organizations must re-examine their hospital harassment policies to ensure those policies include specific prohibitions against gender discrimination and harassment. Hospitals also need to create a workplace conduct policy forbidding bullying or harassment regardless of gender. Once policies are in place, comprehensive training courses should be given to all supervisors and physicians. When policies violated, action should be taken.

\section{Bullying as a Form of Aggression}

Bullying is a form of aggression. Physical bullying is obvious in our society. It tends to be the province of children. Adults are more subtle and devious in their approach, and their bullying can take a variety of forms, many of which may not be obvious to a third party. This allows bullies to continue their activities unchecked and enables them to do what they wish (Paice, 2004). The outburst in the OR by a surgeon or anesthesiologist is not uncommon. Misconduct against nurses is common (Uhari, 1994).

Bullying and mistreatment during training is also a part of the experience of many doctors, medical students or residents (Quine, 2002). Psychological abuse, gender discrimination, and sexual harassment were prevalent in one study (Stratton, 2005). Nursing staff have been implicated in intimidating and harassing residents by verbal comments (Farrell, 1999; Coverdale, 2005); senior residents have also been implicated (Cohen, 2008; Cook, 1996; Daugherty, 1998). Of course, sometime excessive mentorship can be misinterpreted by trainee as bullying. An individual's personal beliefs and lack of self confidence colors their interpretation of any communication; criticism may be inferred where none was implied. Curt behavior by senior doctors may be interpreted as criticism by juniors even when this was not intended. Where the recipient of certain critical or aggressive behaviors is more junior and therefore constrained in their perceived ability to respond to it, this can be a problem (Moscarello, 1994).

A bully tends to be in a position of relative power. This allows him or her to behave towards one or many others in an unacceptable way. This can be as simple as making it impossible for subordinates to progress ups the career ladder by ensuring that they are not given opportunities (Cohen, 2008). Bullies may prevent a subordinate from developing their ideas, and develop them as if they were their own. They may manipulate subordinates to take on unacceptable commitments by playing on their vulnerabilities. The bullies may be perceived as good managers because they get more work done. In the medical world, bullies may avoid taking their fair share of unpleasant tasks in a department. They may do this by offloading some of these tasks onto others who are powerless to protest. If the affected individual does complain, the bully may threaten to activate certain sanctions within their power, to which the victim is vulnerable (Daugherty, 1998). The situation is like that of blackmail. It is not that the victim cannot complain; it is that they perceive themselves as helpless (Cook, 1996; Kozlowska, 1997).

Often bullying is an extension of forms of negative behavior frequently seen in the medical world (Carr, 1997). When and where does it cross the line? Is there then an acceptable level of bullying? Awareness of bullying as a problem has increased, and there is evidence that the prevalence is high in medicine. Nevertheless, there is also the possibility that the behavior experienced by some as bullying is perceived by others as normal (Ahmer, 2009; Quinne, 1999, 2002).

\section{Who Are the Bullies?}

People who are accused of bullying fall into two groups. The first group is those who intend to hurt and humiliate their victim, and who choose their victim with a view to getting pleasure from their power over them. This is uncommon. The second group is made up of people who perceive their behavior as reasonable, while the victim perceives it as bullying. When individuals in this latter group are accused of bullying they are often mortified and suffer a major blow to their self-esteem. Problem situations for this second group often relate to a senior/junior interaction. There are several reasons for this. In the past, senior role models may well have shown bullying behaviors. Many senior doctors are focused, dedicated and, at times, obsessional individuals who do not suffer fools gladly. They are often very self-critical. They expect equal levels of self-criticism, dedication and focus from their junior staff. Where the levels of activity they require from trainees are outside the normal range they are likely to be accused of bullying (Paice, 2004; Daugherty, 1998).

Another category of bully is the medical manager. Frequently, they have been given little training for the task in hand and the demands of the system are often unrealistic. A proportion of these doctors, under pressure, may resort to any method by which they can achieve results, even if this amount to bullying (Houghton, 2003).

Bullying is still part of the organizational culture. For example, even though junior doctors' hours have been agreed, there is, in some specialties, pressure to arrive early and leave late, irrespective of the amount of work to be done. Lastly, even normally amiable senior doctors may behave badly when under personal or professional stress (Johnson, 2009; Roberts, 2009).

\section{Causes of Bullying}

One of the reasons is the lack of training for doctors and sometimes other managers in management or leadership skills. 
They simply may not appreciate that people are different (Daugherty, 1998).

Absence self-criticism may exacerbate bullies' reaction to the confrontational situation. Very self-critical people become depressed, while individuals with low levels of self-criticism have problems in relationships with patients and colleagues (Paice, 2004; Daugherty, 1998).

\section{Why Victims Do Not Speak Out against Bullies?}

Victims of bullying often believe that a complaint would negatively affect their professional progress, and with an intentional bully this might be the case. Thus, incentives to complain are outweighed by the perceived incentives to keep quiet (Margittai, 1996). This creates a "survival" culture, not too far removed from that of prison or the armed forces.

The consequences of bullying are devastating. Bullying is responsible for victims becoming stressed, depressed and intending to leave their jobs. The 2004 study reported that $37 \%$ of doctors in training had been bullied in the past year (Uhari, 1994).

Although there would appear to be a difference between intentional and unintentional bullying, the initially unintentional violator may gain satisfaction or results from this form of behavior, which will then be reinforced. Intentional bullying is a dysfunctional form of behavior which needs intervention and help (Cohen, 2008). Approaches to unintentional bullying should be both educational and organizational. Work with the individual accused of bullying may need to include psychotherapy to explore the reasons for bullying or aggressive behavior. It should also include work on interpersonal and self-awareness skills so that the bully can explore and adopt alternative ways of behaving (Houghton, 2005). This approach, while emphasizing that bullying is unacceptable, also recognizes that bullying behavior may be understandable and that those using it need help to change (Einharsen, 1994). The organizational culture also needs to change. Many companies have put in place clearly defined written policies to prevent bullying and harassment at work, but the problem persists. Management pressures, which essentially amount to bullying, may compel senior doctors to take on impossible clinical loads or to work in unacceptable facilities. They may in turn adopt bullying behavior with subordinates in response to these pressures. The problem may also persist because, although there is more general awareness of the problem, many victims still do not speak out, for a variety of reasons. One appalling truth is that some of these individuals have such low self-esteem that they do not recognize their treatment as bullying (Kozlowska, 1997; Johnson, 2009).

\section{Conclusion}

Hospitals, departments and individual personnel need to develop a higher level of awareness of the problem both in others and in them. Anti-bullying policies should be given a higher profile. This should encourage victims to come forward so that individual bullies can be identified. The unintentional bully will usually, although not always, respond to the strategies outlined above and modify their behavior. They may well respond to personal approaches on the part of the victim. Direct approach of the bully may be counterproductive. The victim should keep a careful record of all behavior they perceive as bullying. It is important to ascertain that what you dealing with are bullying. Once confirmed that you are dealing with bullying, you should approach the bully's line manager or the human resources department. Finally, you could also approach your professional association for advice and support (Houghton, 2004).

We know little about how verbal abuse or bullying is triggered and how it might be prevented (Farrell, 1999). Primary preventive methods include providing educational materials and communication skills training for residents, staff, and educators (Baldwin, 1991). Education on abuse, discrimination, and harassment in the workplace, and how these can be addressed and averted, can also be presented in formal and informal curricula. Such initiatives should promote culture of collegiality and respect for all faculty, staff, and trainees (Quine, 1999). Secondary preventive measures rely on reporting mechanisms. Any occasion of abusive or discriminatory language or behavior needs to be addressed. Measures such as debriefing and supportive counseling should aim to alleviate the psychologically distressing consequences of these behaviors for all recipients and observers. Universal focus on professionalism in medical education and professional behavior of physicians in practice should help us to eradicate this unacceptable behavior (White, 2000).

\section{REFERENCES}

Ahmer, S. et al. (2009). Bullying of trainee psychiatrists in Pakistan: A cross-sectional questionnaire survey. Acad Psychiatry, 33, 335-339. http://dx.doi.org/10.1176/appi.ap.33.4.335

Baldwin, D. et al. (1991). Student perceptions of mistreatment and harassment during medical school: A survey of ten US schools. Western Journal of Medicine, 155, 140-145.

Carr, M. et al. (1991). A survey of Canadian psychiatric residents regarding resident-educator sexual contact. American Journal of Psychiatry, 148, 216-220.

Carr, M. (1997). Comment. Australian \& New Zealand Journal of Psychiatry, 31, 653-654.

http://dx.doi.org/10.3109/00048679709062677

Cohen, J. et al. (2008). The happy docs study: A Canadian Association of Interns and Residents well-being survey examining resident physician health and satisfaction within and outside of residency training in Canada. BMC Research Notes, 1, 105. http://dx.doi.org/10.1186/1756-0500-1-105

Cook, D. et al. (1996). Residents' experiences of abuse, discrimination, and sexual harassment during residency training. Canadian Medical Association Journal, 154, 1657-1665.

Coverdale, J. et al. (2001). A survey of threats and violent acts by patients against training physicians. Medical Education, 35, 154-159. http://dx.doi.org/10.1046/j.1365-2923.2001.00767.x

Coverdale, J. et al. (2005). Protecting the safety of medical students and residents. Academic Psychiatry, 29, 329-331. http://dx.doi.org/10.1176/appi.ap.29.4.329

Daugherty, S. et al. (1998). Learning, satisfaction, and mistreatment during medical internship: A national survey of working conditions. JAMA, 279, 1194-1199. http://dx.doi.org/10.1001/jama.279.15.1194

Einharsen, S. et al. (1994). Bullying and its relationship to work and environment quality: An exploratory study. European Journal of Work and Organisational Psychology, 4, 381-404. http://dx.doi.org/10.1080/13594329408410497

Farrell, G. (1999). Aggression in clinical settings: Nurses’ views: A follow-up study. Journal of Advanced Nursing, 29, 532-541. http://dx.doi.org/10.1046/j.1365-2648.1999.00920.x

Hoosen, I., \& Callaghan, R. (2004). A survey of workplace bullying of psychiatric trainees in the West Midlands. Psychiatric Bulletin, 28, 225-227. http://dx.doi.org/10.1192/pb.28.6.225

Houghton, A. (2003). Bullying in medicine. British Medical Journal, 326, 12. http://dx.doi.org/10.1136/bmj.326.7393.S125a

Houghton, A. (2005). Tips on dealing with bullies. British Medical Journal Career Focus, 330, 201-202.

Huntoon, L. (2004). Abuse of the "disruptive physician” clause. Jour- 
nal of the American Physicians and Surgeons, 9, 68.

Johnson, S. (2009). International perspective on workplace bullying among nurses: A review. International Nursing Review, 56, 34-40. http://dx.doi.org/10.1111/j.1466-7657.2008.00679.x

Joint Commission (2008). Sentinel event alert-Behaviors that undermine a culture of safety.

The Joint Commission (2009). Accreditation requirements. http://www.jointcommission.org/NR/rdonlyres

Kozlowska, K. (1997). Adverse experiences in psychiatric training, part 2. Australian \& New Zealand Journal of Psychiatry, 31, 641-652. http://dx.doi.org/10.3109/00048679709062676

Margittai, K. (1996). Forensic aspects of medical student abuse: A Canadian perspective. The Bulletin of the American Academy of Psychiatry and the Law, 24, 377-385.

Moscarello, R. et al. (1994). Differences in abuse reported by female and male Canadian medical students. Canadian Medical Association Journal, 150, 357-363.

Paice, E. et al. (2004). Bullying among doctors in training: Cross sectional questionnaire survey. British Medical Journal, 329, 658-659. http://dx.doi.org/10.1136/bmj.38133.502569.AE

Quine, L. (2002). Workplace bullying in junior doctors: Questionnaire survey. British Medical Journal, 324, 878-879.

http://dx.doi.org/10.1136/bmj.324.7342.878

Quine, L. (1999). Workplace bullying in NHS community trust: Staff questionnaire survey. BMJ, 318, 228-232.

http://dx.doi.org/10.1136/bmj.318.7178.228

Roberts, S. et al. (2009). The effect of oppressed group behaviors on the culture of the nursing workplace: A review of the evidence and interventions for change. Journal of Nursing Management, 10, 13651374.

Rosenstein, A., \& O’Daniel, M. (2005). Disruptive behavior and clinical outcomes: Perceptions of nurses and physicians. The American Journal of Nursing, 105, 54-64. http://dx.doi.org/10.1097/00000446-200501000-00025

Stratton, T. et al. (2005). Does students' exposure to gender discrimination and sexual harassment in medical school affect specialty choice and residency program selection? Academic Medicine, 80, 400-408. http://dx.doi.org/10.1097/00001888-200504000-00020

Uhari, M. et al. (1994). Medical student abuse: An international phenomenon. JAMA, 271, 1049-1051.

http://dx.doi.org/10.1001/jama.271.13.1049

Vanineveld, C. et al. (1998). Discrimination and abuse in internal medicine residency. Journal of General Internal Medicine, 11, 401-405. http://dx.doi.org/10.1007/BF02600186

White, G. (2000). Sexual harassment during medical training: The perceptions of medical students at a university medical school in Australia. Medical Education, 34, 980-986.

http://dx.doi.org/10.1046/j.1365-2923.2000.00684.x 